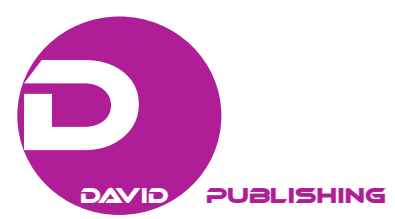

\title{
Topical Issues of Regulation of Economic Relations in Internet Environment
}

\author{
Rasim Alguliyev, Rasim Mahmudov \\ Institute of Information Technology of Azerbaijan National Academy of Sciences, Baku, Azerbaijan Republic
}

\begin{abstract}
This article examines current issues of regulation of economical relations in the Internet environment. Complexities, created by global and virtual features of the Internet economy, are characterized. Problems associated with the implementation of the tax and customs policy, regulation of e-money circulation, virtual labor, intellectual property rights protection and consumer rights, as well as personal information are analyzed. Specifics of economic crimes and problems of their control in a virtual environment are commented. Also, the ways to address these problems are indicated.
\end{abstract}

Keywords: regulation of Internet economy, virtual "brain drain", electronic money, economic cybercrime, criminal economy, protection of personal information

\section{Introduction}

Internet significantly impacts all fields of human activity. Also, economic activity sphere is among fields subject to significant impact of Internet. As a result of this impact, characteristics of economy, its basic principles change, and its coverage area broadens. Some traditional economic activity and professional field lose its significance and are eliminated. New spheres of economic activity and professions emerge. Also, qualitative changes in form and content of traditional economic activity and profession take place.

As an important information and communication infrastructure, Internet is the moving force of economic activity. Informative value and communicativeness are the main factors for increasing the quantity and quality of modern economy. Internet becomes the activity field of mutual relations of both traditional and virtual companies. As a result, specific economic relations are formed in Internet environment. Economy based on capabilities of Internet-Internet economy is formed.

The essence of Internet economy is related to its scientific-content, rather than material-content. In this new economy, information and knowledge become the main manufacturing resources and products. Internet-economy serves to improve the information supply of the population, increase the employment level in fields of intellectual activity, actualize maximum exploitation capabilities of innovation potential, and increase the income (Lehr \& Pupillo, 2009).

Rasim Alguliyev, academician, Institute of Information Technology of Azerbaijan National Academy of Sciences, Baku, Azerbaijan Republic.

Rasim Mahmudov, master's degree, Institute of Information Technology of Azerbaijan National Academy of Sciences, Baku, Azerbaijan Republic.

Correspondence concerning this article should be addressed to Rasim Mahmudov, Institute of Information Technology of Azerbaijan National Academy of Sciences, B.Vahabzade str., 9, Baku c., AZ1141, Azerbaijan Republic. 
Unification of Internet with other means of communication, especially mobile telephones significantly impacts development and broadening of Internet economy. Also, innovative technologies, such as semantic Web, Ipv6, and cloud calculations, rapidly broadening opportunities of using broad-band Internet, and actualization of Internet of things concept promise new perspective for development of Internet economy.

Specific characteristics of Internet are reflected in the new economy. The first characteristic is related to global nature of Internet, its diffusion, and influence in global space. Relatively, national borders are eliminated in economy and a global scale is formed. Foreign manufacturing factors become local manufacturing factors. Differences among national and foreign market, local and foreign partners, local and foreign consumers are eliminated. Second characteristic is related to virtualization of the economy, i.e., via Internet and connected modern technical devices, an individual does not interact with real objects, but their images and symbols instead. Paper and metal money is replaced by virtual money and cash payments are replaced with non-cash payments. Real jobs are replaced with virtual jobs and physical "brain drain" is replaced by virtual "brain drain" (Eliasson, 2013).

Internet is an activity field and a technological sphere with no analogues, non-comparable to any other field, and as a result, it is impossible to regulate social relations, as well as economic activities in this virtual environment using traditional methods. Several economic relations implemented in virtual environment are not recognized in the traditional legal system. The traditional legal system faces several difficult and complex situations, due to technological, virtual, and global characteristics of these relations and their independence from time and location factors. For this reason, development of new regulation methods and mechanisms is in especially topics for ensuring normal activity and development of Internet-economy and supporting the rights of its subjects. For this purpose, initially, research, analysis, classification, and research of relevant solution methods of exiting problems of Internet economy are important tasks for relevant scientific fields.

\section{Economic Problems Created by Global and Virtual Characteristics of the Internet}

If any country becomes a part of a global network economy with developed information infrastructure and transparent electronic (virtual) borders, then it faces serious problems (tax, customs, labor relations, control of export-import operations, protection of intellectual property, etc.) related to implementation of macro-economic policy and regulations of economy. The effect of application of traditional policy in order to avoid foreign negative economic impacts is reduced. At this point, it is impossible to determine the borders of the national segment of economy in Internet environment, because Internet does not recognize national borders. In such conditions, it is very difficult to determine the subjects of economic activity and bring them to make mandatory government payments. It must be considered that regulation of Internet economy can result in significant problems in providing income of state budget, inaccuracies in country payment balance accounts (accounts related to current operations and capital movement), which, in its turn, results in mistakes in calculation of income and expense of the state budget and deformation of its structures. Relevant policies are carried out in traditional economy in order to protect domestic market and support competitiveness of domestic products. Implementation of this policy in internet economy environment is problematic (Brousseau, Marzouki, \& Adel, 2012).

Solution of above-noted issues, firstly, requires elimination of jurisdiction problem in Internet environment. After solution of this problem, any state can apply its economic policy, regulations mechanism, and legislation in Internet environment. One of the most important problems related to Internet regulation is remaining unsolved legislation issues. World-wide application of options, such as modernization of special 
international law, unification of national laws, arbitration, and using technical capabilities in order to determine identity and location of Internet users, are considered as possible methods to solve jurisdiction problems in Internet environment (Kohl, 2010).

Besides, Internet related legislation base of world countries is not sufficient to regulate social relations (as well as in economic field) within Internet environment. Legislators are not able to promptly react to new realities formed in virtual environment by rapidly developing Internet technologies. This is related to complexity of comprehension of the virtual environment for traditional law theory. Despite all difficulties, Internet Governance Forum engaged in solution of administration and regulation problems in virtual environment under UN mandate, relevant specialized institutions of the UN attempt to solve legal problems related to Internet, develop model laws and recommendations for countries. Due to the global nature of Internet, each country is obliged to internationally cooperate in this field in order to form and develop national Internet legislation (Kurbalija, 2012).

\section{Regulation Problems of Virtual "Brain Drain", Virtual Labor Relations}

The economy rapidly globalizing, due to the impact of Internet, creates new forms of manufacturing and labor organization. Creation of new employment types and forms creates new relations between employees and employers. These relations are impossible to regulate within the framework of traditional legislation and social norms. Economic crisis and globalization of economy affect forms and types of employment differently. Especially, globalization processes in international labor market attract more economically active part of the population from different countries to its orbit. A strict selection is carried out - the most qualified, flexible, and motivated specialists gather in the global labor market (Olaoye, Dabiri, \& Binuyo, 2011).

Due to development of Internet technologies, new employment forms are created, with work timetables and routine distribution that are flexible in terms of time and place. Effectiveness of relevant employment types is measured by their flexibility, efficiency, and productivity. This process is directly related to "brain drain" problem. If authors approached this issue from macro-economic interests' standpoint, the employer profits and the executor loses (Kleinschmidt, 2006). Whereas the employees remain in their home countries and meet their material demands, the intellectual portion of the national human capital is used abroad. This is a direct loss of gross domestic product (GDP). Mechanisms for protection of national labor market from "brain drain" have not been developed in any world country. The developed countries gain triple revenue from using the intellectual labor of the citizens of developing countries:

(1) Saving on expenses for education and training of intellectual workers;

(2) Saving on expenses (such as residence, transportation, and social insurance) by paying reduced wage to these workers as cheap labor force;

(3) Using the intellectual labor of citizens of other countries is an increase in GDP in this country (Docquier \& Rapoport, 2011).

Traditional labor legislation does not consider the characteristics of Internet environment and virtual labor. This creates significant problems in legal regulation of virtual labor relations. Main problems are related to definition of the virtual workplace and working hours, controlling work discipline, etc. In Internet environment, agreement between the employer and virtual employee does not include a solution to issues, such as payment of wages, vacation, business trips, capability development, temporary loss of working capability, violence of labor agreement, etc. In many cases, parties of virtual labor relations are active in different countries. This creates 
additional problems for regulation of labor relations. For this reason, labor legislation system must be renewed taking the characteristics of the virtual environment into account (Sullivan, 2012).

\section{E-money Regulation Problems}

Cash payment allows keeping the personal information of the product buyers confidential. For this reason, cash payments are preferred in many crimes. Demand for anonymous payments resulted in development of electronic payment systems and electronic money. Electronic money does not require identification or official emission. For this reason, law enforcement authorities cannot track electronic money flows directed towards criminals (FATF Report, 2010).

Using modern electronic payment systems, development of Internet-banking and electronic settlement of accounts accelerate the money turnover speed. As a result, several problems occur: regulation of money turnover, inflation of electronic money, and its impact of economic development. Another question arises due to the occurrence of new types of money, such as who will monitor this money and who will gain the profit using them.

The perspective of partial replacement of traditional payments by e-money creates certain concerns. First, e-money circulated and broadly used by private companies can significantly reduce the effectiveness of money policy and stimulate the inflation process as a result. Second, e-money users are defenseless from legal point of view. Third, e-money has become a convenient tool for laundering dirty money and financing terrorism (Murray, 2013). Regulation of e-money turnover primarily assists in the solution of following problems:

- creating conditions for meeting the demands of population and enterprises in technological payment services;

- protecting the rights of relevant service users;

- providing fair competition with other payment service providers (firstly, banks).

It must be noted that, from legal standpoint, e-money does not replace traditional money. For this reason, consideration of following for implementation of state policy related to regulation of e-money is necessary:

- Relevant institutions (Central Bank) must be overseeing activities relating to turnover of e-money;

- It must be a sufficient level of guarantee of protection of the consumers from financial fraud.

Normative acts regulating legal relations related to e-money emission and turnover have been enforced in the European Union as of 2000. In relevant legislation, rights related to emission of e-money are solely granted to credit organizations (Büllesbach, Poullet, \& Prins, 2006).

\section{Intellectual Property Right Protection Problems}

There are several existing problems related to protection objects of intellectual property rights in Internet environment. As these problems do not exist in traditional legal practice, development of new methods and mechanisms is required for solution of these problems. Use of Internet is also essentially important for business and entrepreneurship environment. Thus, businessmen gain the ability to cheaply advertise their commodity and services worldwide, inform wide audience, and create close and operative connection with consumers. Besides, it is possible to organize a more efficient sale of products, primarily of program products, works of science, literature, and art. Internet is also used for rendering certain services, for example, distant service of software installed on servers, consultancy services, other services of information nature, and services directly linked with Internet activity and its use. Rendering such services is related to objects of intellectual property 
rights at a certain extent, for example, information provided while rendering information services, as well as changes made in computer software distantly can be protected through author's rights (Marginson \& Murphy, 2009).

Searching in Internet, posting and transferring information, and familiarization of users with objects of author's or related rights that are placed in the global network directly concern intellectual property rights. Entrepreneurs also use individualization tools of their products, works, and services - trademarks, origin name, and brand names. Also, new individualization tools - domain names have been created. Conflicts between those who register domain name and proprietors of traditional trademarks are often encountered in practice. Finally, there is a fundamental contradiction between territorial characteristics of intellectual property rights and virtual and global nature of Internet. This contradiction also creates substantial complexities in application of traditional legislation of intellectual property relevant relations in Internet. As there are no national borders in Internet, solution of problems related to protection of intellectual property requires development and acceptance of international norms directed at unification of relevant national legislation systems (Pupillo, 2009). It must be noted that, although several international agreements adopted to-date reflect norms concerning protection of authors' and related rights, they regulate general issues and do not solve many conflicts that occur in this field. For this reason, there is a grave necessity for adopting special international convention related to protection of intellectual property right on Internet. These conditions, on one hand, result in increasing of intellectual property rights violation on Internet, and on the other hand lead to misbalance between the interests of the society and the consumers, benefiting the latter. Undoubtedly, from the social interests' standpoint, larger amount of literature, works of art, motion pictures, software and data base in Internet is better for society. But often, placing one or other materials on Internet violates author's rights or creates conditions for it. Thus, information exchange freedom has positive and negative results. So far, a strategy which is accepted by the entire society to achieve a balance between digital product manufacturers and consumers has not been developed in any country (Pager \& Candeub, 2012).

Crimes related to trademarks are similar to crimes related to author's rights. The gravest forms of these crimes are as followings (Kurbalija, 2012):

- using trade marks for fraud and selling low-quality products;

- crimes committed due to domain names.

Positive image of a company is directly related to its trade mark. Criminals use trade marks for some operations using fraud, for example, Internet users are sent millions of e-mails on behalf of any company using their trade marks.

Other crimes related to trademarks are related to domain names. Cybersquatting can be sited as an example for this, i.e., a domain name identical or close to the trade mark of any product or company is illegally registered. Later, that domain is sold for a high price or that domain name is used to sale of certain products of services on behalf of the company under the name of which it was registered.

\section{E-commerce Regulation Problems}

One of the main characteristics of electronic commerce is its coverage of global space due to capabilities of Internet. For this reason, implementation of a single regulation policy in this field for all countries is required. Determination of legislation system isolated from global space on a national level creates legal contradiction in implementation of international electronic payments. 
One of the points at issue awaiting its solution in electronic commerce field is related to the change of classification of audio-products depending of their delivery form (compact disc (material form) or via Internet (non-material form)) to the buyer (Kurbalija, 2012). As a final result, the same audio-product receives a different commodity status depending of the method of its delivery to the buyer and is held liable for different types of taxes and customs payments. From this standpoint, implementation of relevant classification is very important, because commodity from this standpoint, implementation of relevant classification is very important, because different legal norms are applied to commodity and service sale.

Another important issue is related to precise determination of the legal status of "electronic commerce" notion. Thus, this is an issue of a practical and legal importance. In case of recognition of the legal status of the electronic trade, special regulation norms will be applied to this activity type (as well as tax and customs payments field) (Blythe, 2011).

From the standpoint of the US government, the main criterion distinguishing electronic trade from traditional trade is the obligation to sell products and services in on-line mode. This means that, any commercial transaction gained in on-line mode (even if its implementation implies to physical delivery of a product) is considered as electronic commerce, for example, purchasing of a book through amazon.com web-site is considered as electronic trade, despite the fact that the book is delivered through an ordinary post service. According to the definition of World Trade Organization (WTO), electronic commerce is electronic manufacturing, advertising, sale, and delivery of commodities and services (WTO, 1998).

Currently, there are several existing concepts related to regulation of e-commerce in the world:

1. Leaders of information technologies field-USA, Japan, Canada, South Korea, Australia, and other countries pursue a policy of non-interference (or minimal interference) of state to Internet economy and there is a tax payment postponement permission granted to this segment of the economy. The objective is to stimulate the development of this field. In 1998, US Congress adopted a six year Tax Exemption Law. In 2004, this law was prolonged for three years. In 2007, validity period of this law was prolonged for another seven years (Blythe, 2012).

Some specialists think that tax postponement significantly damages budget interests of a country. At the same time, e-commerce representatives think that tax postponement elimination can significantly hinder development of Internet economy in the country. USA recommends its policy pursued towards Internet economy to other developed countries.

2. European Union countries are interested in eliminating the gap in taxation of e-commerce activity field. These countries are building their own internal and external tax policy based on the concept of maximum government regulation of electronic economic relations, i.e., these countries focus on budget and tax policy (Savin, 2013).

Different concepts have been proposed in regards to this policy, for example, experts of Eschmann University of Belgium proposed that meters are installed and transmitted information volume (traffic) is paid for. In this approach, information is evaluated based on its quantity, not its quality. Formerly, according to the calculations of the Belgian Communication Ministry, if case of assigning a 1 dollar fee per 100 megabytes used, the country could earn 10 billion dollar a year. This constitutes 4\% of GDP in Belgium (Basu, 2013).

Taxation of subjects of e-commerce activity of France assumes their obligatory certification of their activity. As of 2000, French Internet users have been prohibited from buying products from companies that are uncertified and do not pay taxes to perform e-commerce activities (Miller \& Cross, 2012). 
Addition of a new fiscal payment - "tax for using Internet network for business purposes" to existing tax system is considered in Germany. Such taxation is connected to consideration of Internet as a manufacturing tool. Only legal persons that are residents of the country and use Internet to gain profit can act as relevant tax payers. In this case, the time spent by the legal person to connect from his computer to Internet for entrepreneurship purposes is calculated as tax payment period. "Internet" column must be filled while compiling tax declaration. Internet connection period is specified in this column (Basu, 2013).

This idea of Germany is also reflected in the legislation of Switzerland. But in 2000, the parliament of this country confronted taxation of economic activities performed through Internet. It was declared that VAT will not apply to non-material commodities obtained through Internet.

Solution of following issues in Internet regulation field is an important field for provision of normal activity and development of electronic commerce in general (Kurbalija, 2012):

- Providing use of broad-band Internet and high-quality service is one of the most important conditions of rapid development of electronic commerce in multimedia field (for example, distribution of audio-video products);

- Providing Internet security must increase reliability and durability of electronic commerce environment; this is one of the necessary conditions for strengthening the confidence of the participants of the relevant field;

- Information coding is important for protection of communications under the conditions of performance of financial operations;

- Solution of jurisdiction issues is important in terms of providing reliability of electronic commerce, especially protecting rights of consumers;

- Due to increasing volume of trading operations of non-material products, protection of intellectual property rights is becoming especially important for electronic commerce;

- Using electronic signature simplifies implementation of trading operations and solves identification problems;

- As large amounts of information are collected about the buyers in electronic commerce process, protection of personal information is relevant in terms of protecting personal lives.

\section{Shadow Economy Battling Problems}

Shadow economy is an economic activity field without an official registration, i.e., shadow economy includes types of activities that are legally allowed, but carried out without a permission (Schneider, 2004). If economic activity is carried out without registration and permission, quality problems occur in this field due to lack of control in the relevant field, obligatory payments are not made to the government, social protection of the workers is not provided. Measuring shadow economy and determining its scale is a sufficiently difficult issue. Shadow economy is of closed nature due to the fact that it is illegal. For this reason, shadow economy is measured using indirect methods. In comparison with traditional economy, the capacity of shadow economy is higher in Internet economy. Thus, Internet is an environment of anonymity, there are several existing objective and subjective complexities in regulation field of legal and economic relations. Many business subjects are operating in Internet without a license or registering for taxation.

Several reasons of occurrence of shadow economy in traditional economy are similar for the Internet economy as well. In both spheres, the main reasons of the problem include inefficiency of regulation, strict legal conditions, and high level of taxes. For this reason, solution of this problem includes simplification of 
Internet-entrepreneurship conditions, reducing tax load, eliminating bureaucratic hindrances, creating an effective protection system of intellectual property rights, and building an international partnership in terms of legal regulation of this field with consideration of characteristics of the global network.

\section{Criminal Economy Battling Problems}

Criminal economy stands for legally prohibited types of activity. Approximately a million people become victims of Internet crime worldwide on a daily basis. Annually, the victims of cybercriminals lose approximately 500 billion dollars worldwide. Cybercrime has become a more profitable criminal field surpassing drug related crimes. According to information from early 2013, 45\% of financial institutions worldwide have been subject to attacks of hackers during the past year (Center for Strategic and International Studies, 2013). In accordance with research results of United Nations Office on Drugs and Crime (UNODC), cybercrime cases directed at financial sector of economy are rapidly increasing. The results of the survey conducted among 3,877 companies representing 78 countries prove this idea (UNODC, 2013).

Cybercrime is characterized as a higher profitable criminal field with a lower level of risk. Thus, cybercrime is an environment far from control and with weak legal regulation. Rapid development of economic relations in Internet field also results in increasing the level of cybercrimes of economic nature. For this reason, protecting the rights of consumers on Internet, forming confidence environment for businesses, and increasing e-commerce and security of online communication become important issues. Technical problems resulting from national borders and control are among main factors causing difficulties in struggle with cybercrime. International cooperation in this is not durable and regular. In transitional and developing countries, necessary basis for fighting cybercrime has not been formed yet.

Laws concerning trade with certain products have been adopted in many countries. Some countries legally limit the sale of arms and ammunition, while others allow their free trade. There is a similar situation regarding pharmaceuticals. Some countries do not place any restrictions for sale of pharmaceuticals, while others perform their sale solely based on prescription. International trade performed over Internet creates difficulties for application of such limitations related to sale of some products. Internet-stores operating in countries that do not place any limitation can sell their products to the citizens of the countries where such limitations are being enforced. Until the advent of Internet, instructions for making arms were inaccessible for the majority. Nowadays, such instructions are accessible on Internet (Cejp \& Scheinost, 2012).

Swindles carried out using computers are among most popular crimes on Internet, i.e., it allows the criminal to conceal their personal information through automation and apply software. Automation gives the criminals superiority while performing some operations. Letters from Nigeria can be sited as examples for such swindles.

Although such crimes are performed using computers, these crimes are reflected in criminal legislation of many countries as ordinary swindle, instead of computer crime.

One of the most spread forms of swindle on Internet is swindling through online auctions. Currently, online auctions are one of the most popular services of e-commerce. Through this service, buyers have access to different products from any desired point of the world. Sellers can accept offers stimulating increasing of the price from any location in the world.

Malicious people performing crimes at auctions use the lack of personal relations between buyers and sellers. Difficulties forthcoming from different location of the real user and the criminal turn the auction 
swindling into the most popular cybercrime. This type of crime has the most spread following two forms (International Telecommunication Union, 2009):

- Selling inexistent products and requiring advance payment from the buyer before its delivery;

- Purchasing products and requiring its delivery without the intention of paying for it.

Internet creates new opportunities for laundering dirty money. Online financial services allow performed multiple financial operation in a very short period of time, at a great pace. Internet serves the elimination of dependence from cash operations. Non-cash payments replacing cash payments were the first step towards elimination of physical dependence from money. Determination of strict procedures regarding suspicious non-cash transfers resulted in emergence of new methods of the criminals. Detection of suspicious operations in dirty money laundering field lays upon financial institutions participating in these operations. Currently, there are restrictions in regulations of money transfers. Internet allows criminals to transfer money abroad cheaply and avoid paying taxes. Difficulties of investigating methods of laundering of dirty money are currently related to use of virtual currencies and online casinos (Turner, 2011).

Criminal economy battling strategy must be an important component of cybersecurity strategy. Dialogue and international cooperation must be built for effective battle with this problem; international reactions must be connected to growing problems in cybercrime field.

In order to effectively fight criminal economy on an international scale, relevant legislation acts must be adapted, citizens must be educated, and private sector must be sufficiently supported. In general, legal, technical, and organizational measures must be considered for a complex approach to solution of the field.

Legal measures attain more importance in this instance. Firstly, these measures implicate inclusion of propositions related to cybercrime actions (computer fraud, illegal access, theft of information, violating intellectual property rights, etc.) to criminal legislation. Besides, law enforcement officials need special mechanisms and tools for investigation of cybercrimes. Considering the international scale of cybercrimes, relevant legislation must determine the legal bases of international cooperation in this field.

Technical issues play an important role during investigation of cybercrime, for example, certain procedures must be carried out in order to protect the integrity of digital evidence. Another problem is connected to development of technical protection tools. Reliably protected computer systems are difficult to attack.

Technical protection measures must be applied to all elements of technical infrastructure. Two potential purposely groups can be determined for protection of Internet users and institutions:

- end users and institutions;

- service providers and software developing companies.

Effective fight with cybercrime requires developed organizational structures and training of users, for example, if a user knows that financial institution will never contact him/her in order to obtain his/her password or bank account information, he/she will not be a victim of the criminals. Users must be informed and instructed about possible threats in order to limit the number of potential cybercriminals (Yazdanifard, Oyegoke, \& Seyedi, 2011).

\section{Consumer Rights Protection Problems in Internet Environment}

As noted, providing consumer right is one of the main conditions of a successful e-commerce activity. As e-commerce is a new field, general consumers do not demonstrate much confidence in it. Electronic commerce 
is a completely new activity field, for this reason, consumer does not have as much confidence in this system, as in traditional commerce. Protection of consumers' right is an important legal tool for strengthening the confidence in electronic commerce.

Regulation of Internet economy must protect consumers from dishonest advertising, low-quality commodities and services, theft and illegal transfer of personal financial information (for example, payment card information), etc. The distinctive characteristics of Internet economy are protection of consumer rights on an international level. This characteristic is not a prioritized issue for traditional economy. If formerly consumers rarely needed international protection, as a result of development of electronic commerce, trade transactions surpass national borders. Relatively, topicality of issues related to jurisdiction increases (Portela, 2010).

First approach is more convenient for sellers and is based on "origin countries" or "sellers make arrangements" principals. Institutions engaged in electronic commerce are superior in such scenario, as they always operate in visible and familiar legal environment.

Second approach, firstly, protects the interests of consumers and is based on "assignment countries" principals. Here, the main problem for companies is the possibility of colliding with different legal systems. One of the mechanisms implicating the solution of this dilemma is the unification of legislations of different countries in consumer rights protection field.

Future development of Internet economy requires unification of legislations of different countries or creation of the new international regime for protection of consumer rights.

\section{Personal Information Protection Problems}

Although Internet-technologies are effective tools for collection and use of personal information, they create strong threats for inviolability of personal life. Solution of this problem carries both economic and social importance. For this reason, this situation requires review of Internet policy. Firstly, confidentiality mode of Internet services must be provided. Justifying confidence of the consumer requires providing inviolability of his/her security and personal life. One of the main issues conditioning the development of Internet economy is winning consumer confidence. It is true that certain legislation acts recognize the rights of citizens as consumers. But technical supply is not sufficient for provision of these rights (Hildebrandt, O'Hara, \& Waidner, 2013).

It must be considered that certain personal information is important for rendering Internet services. Also, successful development of Internet economy is directly dependent on simple collection, analysis, and use of personal information. For this reason, application of limitations regarding use of personal information can hinder development of Internet economy.

Another problem is related to preparation of confidentiality policy realization mechanisms that can promptly react to rapid development of Internet innovations.

Preparation of a single policy on an international level related to protection of commercial confidentiality is necessary, as Internet economy covers a global area. Discrepancies among relevant national legislation acts create additional problems for development of Internet economy. At the same time, national-cultural differences create difficulties in creating single policies in this field.

Confidentiality policy can be successfully developed under the conditions of active participation of all interested parties in this process. Thus, participation of business, citizen society, science and technical societies, 
as well as government institutions in this process is important. Otherwise, developed policy will not reflect all interests.

\section{Conclusions}

Research and analysis demonstrate that conducting several regulating measures in Internet environment is necessary for forming and developing normal economic relations. Information is the main product and trade object of Internet economy. For this reason, providing information security in Internet environment is one of the important conditions of economic security. Otherwise, Internet can become a convenient environment for criminal economy. Another important issue is the solution of jurisdiction problem. Implementation of economic policy of the government and effectively battling economic crime in Internet environment directly depends on the solution of the problem. Also providing intellectual property rights also carries importance for Internet economy. This is topical in terms of protection of personal information, protection of personal life, and gaining consumer confidence due to collection of a vast amount of information about buyers during the e-commerce process, which is one of the main segments of Internet economy.

Solution of all these problems requires a complex approach on an international level. Although Internet has national segments, in general, it has a global nature. Economic relations in Internet environment mainly cover a global environment. For this reason, unlike traditional economy, regulation of economic relations on Internet requires more global consensus. The definition experience of the legal status of international air and water space, the Antarctic, and cosmic space can be useful for legal regulation of Internet.

Currently, information economy, its important direction-Internet economy, is the most dynamically developing economic activity field. The share of this field in the volume of GDP of the countries is rapidly increasing. For this reason, international organizations and governments are obliged to pay more attention to solution of economic relations regulation problems in Internet environment. A flexible legislation system that can adequately meet dynamic development rate of information technologies on international and national levels must be formed.

\section{References}

Basu, S. (2013). Global perspectives on e-commerce taxation law. Farnham: Ashgate Publishing, Ltd.

Blythe, S. E. (2011). E-commerce law around the world: A concise handbook. Bloomington: Xlibris Corporation Publishing.

Blythe, S. E. (2012). An e-commerce law for the world. Bloomington: Xlibris Corporation Publishing.

Brousseau, E., Marzouki, M., \& Adel, C. (2012). Governance, regulation and powers on the Internet. Cambridge: Cambridge University Press.

Büllesbach, A., Poullet, Y., \& Prins, C. (2006). Concise European IT law. Alphen aan den Rijn: Kluwer Law International.

Cejp, M., \& Scheinost, M. (2012). Organized and economic crime: A common problem. Crime and Transition in Central and Eastern Europe, 6, 157-178.

Center for Strategic and International Studies [CSIS]. (2013). The economic impact of cybercrime and cyber espionage. Santa Clara: McAfee Inc.

Docquier, F., \& Rapoport, H. (2011). Globalization, brain drain and development. Bonn: IZA Discussion Papers Series.

Eliasson, G. (2013). The Internet as a global production reorganizer: The old industry in the new economy. Long Term Economic Development. Economic Complexity and Evolution, 2, 243-271.

FATF Report. (2010). Money laundering using new payment methods. Retrieved from http://www.fatf-gafi.org/media/fatf/documents/reports/ML\%20using\%20New\%20Payment\%20Methods.pdf

Hildebrandt, M., O’Hara, K., \& Waidner, M. (2013). Digital enlightenment yearbook 2013: The value of personal data. Amsterdam: IOS Press. 
International Telecommunication Union [ITU]. (2009). Understanding cybercrime: A guide for developing countries. Retrieved from http://www.itu.int/ITU-D/cyb/cybersecurity/docs/ITU_Guide_A5_12072011.pdf

Kleinschmidt, H. (2006). Migration, regional integration and human security: The formation and maintenance of transnational spaces. Farnham: Ashgate Publishing, Ltd.

Kohl, U. (2010). Jurisdiction and the Internet: Regulatory competence over online activity. Cambridge: Cambridge University Press.

Kurbalija, J. (2012). Internet governance. Geneve: DiploFoundation.

Lehr, W. H., \& Pupillo, L. (2009). Internet policy and economics: Challenges and perspectives. New York: Springer.

Marginson, S., \& Murphy, M. (2009). Creativity and the global knowledge economy. Bern: Peter Lang.

Miller, R., \& Cross, F. (2012). The legal environment today: Business in its ethical, regulatory, e-commerce, and global setting. Boston: Cengage Learning.

Murray, A. (2013). Information technology law: The law and society. Oxford: Oxford University Press.

Olaoye, I. K., Dabiri, M. A., \& Binuyo, A. A. (2011). ICT, globalization and the labour market: Turning brain drain to brain gain. European Journal of Business and Management, 3, 139-145.

Pager, S. A., \& Candeub, A. (2012). Transnational culture in the internet age. Cheltenham: Edward Elgar Publishing.

Portela, I. M. (2010). Information communication technology law, protection and access rights: Global approaches and issues. Calgary: Idea Group Inc.

Pupillo, L. M. (2009). Intellectual property, digital technology and the developing world. Internet Policy and Economics, 6, 79-98.

Savin, A. (2013). EU Internet law. Cheltenham: Edward Elgar Publishing.

Schneider, F. (2004). Shadow economy. The Encyclopedia of Public Choice, 1, 286-296.

Sullivan, C. (2012). Remote working and work-life balance. Work and Quality of Life, International Handbooks of Quality-of-Life, 2, 275-290.

Turner, J. E. (2011). Money laundering prevention: Deterring, detecting, and resolving financial fraud. Hoboken, New Jersey: Wiley.

UNODC. (2013). Comprehensive study on cybercrime. Vienna: UN Publishing.

World Trade Organization [WTO]. (1998). Declaration on global electronic commerce. Retrieved from http://www.wto.org/english/tratop_e/ecom_e/mindec1_e.htm

Yazdanifard, R., Oyegoke, T., \& Seyedi, A. P. (2011). Cyber-crimes: Challenges of the millennium age. Advances in Electrical Engineering and Electrical Machines. Lecture Notes in Electrical Engineering, 134, 527-534. 